\title{
APUDOMAS PANCREÁTICOS: UM DESAFIO PARA CLÍNICOS E CIRURGIÕES
}

\section{PANCREATIC APUDOMAS: A CHALLENGE FOR SURGEONS AND PHYSICIANS}

\author{
Olívio Louro Costa, TCBC-ES ${ }^{1}$ \\ Maria da Penha Zago ${ }^{2}$ \\ Maria C.S. Santos ${ }^{3}$ \\ Carlos Musso $^{4}$ \\ Iúri Drumond Louro ${ }^{5}$
}

\begin{abstract}
RESUMO: Objetivo: O propósito do presente estudo é analisar as dificuldades quanto ao diagnóstico, avaliação prognóstica e conduta em sete pacientes portadores de tumores neuroendócrinos do pâncreas (apudomas), estudados na última década, comparando os resultados com aqueles discutidos na literatura. Método: A idade dos pacientes variou de 15 a 66 anos, com média de 38,4 anos. Todos foram submetidos a alguma forma de ressecção pancreática por tumores neuroendócrinos. Os exames histológicos foram feitos pelas técnicas tradicionais e por imuno-histoquímica. Resultados: Três pacientes tiveram um diagnóstico inespecífico de tumor neuroendócrino; dois de vipoma e dois de gastrinoma. As síndromes não se manifestaram claramente, ainda que cada caso tenha tido um rótulo diagnóstico. Os exames por imuno-histoquímica demonstraram a presença de múltiplos hormônios, mas por falta de sintomas clínicos, as correlações ficaram prejudicadas na maioria dos casos, havendo correlação somente em caso de gastrinoma. Um paciente faleceu no pós-operatório; um sobreviveu sete anos e cinco estão vivos, com sobrevida variando entre três e cinco anos. Conclusões: Não houve uma manifestação sindrômica evidente, porém a sobrevida dos pacientes tem sido compatível com os dados de literatura.
\end{abstract}

Descritores: Apudomas; Tumores neuroendócrinos; Carcinóides; Gastrinomas; Vipomas; Tumores de ilhotas.

\section{INTRODUÇÃO}

Os apudomas do pâncreas são também conhecidos como tumores de ilhotas, mas acredita-se que tais tumores não se originem de células das ilhotas de Langerhans, mas sim de células ductais pluripotentes, explicando, assim, a capacidade de diferenciação neuroendócrina ${ }^{1}$.

Não existe critério histopatológico confiável, capaz de discernir entre a malignidade ou a benignidade de tais tumores, reservando, assim, a classificação de maligno aos tumores que apresentam metástases ${ }^{2,3}$. Também não há estadiamento TNM para estes tumores, e o prognósti- co de cada caso depende do subtipo funcional, da possibilidade de ressecção cirúrgica completa, da extensão anatômica, assim como da presença de metástases ${ }^{3-6}$. Os tumores neuroendócrinos do pâncreas são notáveis pela capacidade de secretar hormônios diversos na circulação sangüínea, causando, assim, de acordo com o tipo e a quantidade do hormônio produzido, síndromes características (Tabela 1). A classificação do tumor como funcionante depende da presença detectável de uma das síndromes clínicas conhecidas e geralmente a própria nomenclatura do tumor deriva da síndrome por ele causada ${ }^{7,8}$ (Tabela 1). Deste modo, são classificados como não-funcionantes os

1. Professor Livre-docente do Departamento de Clínica Cirúrgica do Centro Biomédico da Universidade Federal do Espírito Santo, CBM/UFES

2. Professora do Departamento de Clínica Médica do CBM/UFES

3. Médica Residente do Serviço de Anatomia Patológica do Hospital Universitário Cassiano Antonio Moraes, HUCAM/ UFES

4. Professor do Departamento de Patologia do CBM/UFES

5. Research Associate - Department of Hematology/Oncology, University of Alabama at Birmingham, Birmingham, AL, USA

Recebido em 12/02/2001

Aceito para publicação em 16/10/2001

Trabalho realizado no Serviço de Clínica Cirúrgica, Gastroenterologia e Anatomia Patológica do HUCAM/UFES 
tumores que não provocam manifestações sindrômicas características. A maioria destes tumores não-funcionantes secreta pelo menos um peptídeo hormonal detectável por imuno-histoquímica, sem causar manifestações clínicas clássicas. Isto se deve ao tipo do hormônio secretado, à quantidade do peptídeo na circulação sistêmica, ou ainda à inabilidade de exportar tais hormônios para o meio extracelular, neste último caso ocorrendo a positividade no exame imuno-histoquímico, mas a ausência do hormônio na circulação sangüínea ${ }^{9,10,11}$.

O propósito do presente estudo é analisar as dificuldades quanto ao diagnóstico, avaliação prognóstica e conduta em sete pacientes portadores de tumores neuroendócrinos do pâncreas (apudomas), estudados na última década, comparando os resultados com aqueles relatados na literatura.

\section{MÉTODOS}

Foram analisados sete pacientes portadores de apudomas pancreáticos, operados e acompanhados no Serviço de Clínica Cirúrgica do HUCAM/UFES, no período de janeiro de 1990 a janeiro de 2001. Os exames histopatológicos foram realizados no Serviço de Anatomia Patológica do HUCAM e reestudados em outros serviços, para execução de exames imuno-histoquímicos. Foram analisados os dados relativos à qualificação dos pacientes, resultados histopatológicos, correlação clinicopatológica e evolução.

\section{Caso 1}

Homem, 42 anos, branco, internado com dores na região epigástrica iniciadas há três meses e que se tornaram muito intensas no último mês. Queixava-se de fraqueza muscular e emagrecimento de três quilos. Não tinha queixas de diarréia, nunca se tratara por úlcera péptica, nem tinha lesões de pele. Uma endoscopia digestiva alta mostrou lesão ulcerada de corpo gástrico, cuja biopsia foi compatível com neoplasia maligna. À cirurgia encontrouse tumoração dura, envolvendo corpo e cauda de pâncreas, invadindo por contigüidade o baço, o estômago e o pólo superior do rim esquerdo. Foi realizada a gastrectomia total, com pancreatectomia, esplenectomia, supra-renalectomia e ressecção do pólo acometido do rim, em monobloco. O resultado histopatológico foi "tumor do sistema APUD", com bordas livres de comprometimento. Não foram encontradas metástases nos linfonodos e a suprarenal estava histologicamente preservada. O paciente apresentou uma pequena fístula digestiva, que cicatrizou espontaneamente em um mês. Continuou em sua atividade profissional durante sete anos, quando se reconheceu a recidiva da doença e faleceu.

\section{Caso 2}

Mulher, 66 anos, negra, referia dores no flanco esquerdo, com evolução de cinco anos, descrevendo piora nos últimos dois anos. Não havia qualquer manifestação clínica sugestiva de tumor neuroendócrino. O exame físi-

Tabela 1

Relação entre os produtos secretados por APUDomas e os sintomas clínicos associados

\begin{tabular}{|c|c|c|}
\hline Tumor & Produto secretado & Sintomas na síndrome \\
\hline Insulinoma & Insulina & Hipoglicemia, distúrbios neurológicos \\
\hline Glucagonoma & Glucagon & Diabetes, rash cutâneo, estomatite \\
\hline Gastrinoma & Gastrina & Dor abdominal, úlceras, diarréia, sangramento gastrintestinal \\
\hline Somatostatinoma & Somatostatina & Diabetes, esteatorréia, acloridria \\
\hline Ppoma & Polipeptídeo pancreático & $\begin{array}{l}\text { Altas taxas séricas de polipeptídeo pancreático, mas } \\
\text { clinicamente silencioso }\end{array}$ \\
\hline Vipoma & Polipeptídeo intestinal vasoativo & $\begin{array}{l}\text { Diarréia aquosa, hipocalemia, acloridria. Quando completa, a } \\
\text { síndrome é conhecida como síndrome de Verner-Morrison }\end{array}$ \\
\hline ACTHoma & $\mathrm{ACTH}$ & $\begin{array}{l}\text { Síndrome de Cushing (obesidade, fraqueza muscular, } \\
\text { intolerância à glicose e hipertensão) }\end{array}$ \\
\hline Carcinóide & Serotonina & Síndrome carcinóide (diarréia e flushing). \\
\hline $\begin{array}{l}\text { Carcinoma misto } \\
\text { (ductal/endócrino) }\end{array}$ & $\begin{array}{l}\text { Raro. Qualquer peptídeo } \\
\text { anteriormente mencionado, } \\
\text { associado ao componente } \\
\text { ductal }\end{array}$ & $\begin{array}{l}\text { Prognóstico não estabelecido. Diferenciação ductal em } 25-30 \% \\
\text { das células. Estes tumores podem ser classificados segundo o } \\
\text { padrão TNM }\end{array}$ \\
\hline
\end{tabular}


co era normal. A ultra-sonografia (US) e tomografia computadorizada (TC) revelaram massa lobulada, de contorno irregular, na cauda do pâncreas. Realizada a ressecção do corpo e cauda do pâncreas, a paciente evoluiu com infecção do sítio cirúrgico, hemorragia incontrolável e óbito. O diagnóstico histológico foi de tumor neuroendócrino. Exames de imuno-histoquímica revelaram coloração positiva para peptídeo intestinal vasoativo (vipoma) e somatostatina e negativa para queratina, serotonina, sinaptofisina, polipeptídeo pancreático (ppoma) e insulina. O diagnóstico final foi de tumor de ilhotas, compatível com vipoma.

\section{Caso 3}

Mulher, 60 anos, branca, teve episódios de dor em cólica, no andar superior do abdome, com vômitos eventuais e emagrecimento importante. Ao exame físico havia massa epigástrica de consistência firme e limites imprecisos. Exames por US e CT demonstraram litíase biliar e massa de corpo de pâncreas. Foram realizadas colecistectomia e ressecção do corpo e da cauda do pâncreas, cujo exame histológico peroperatório revelou neoplasia maligna. O diagnóstico final foi de tumor neuroendócrino, associado a carcinoma de células acinares. $\mathrm{O}$ exame por imuno-histoquímica revelou positividade para sinaptofisina, peptídeo intestinal vasoativo e somatostatina. As reações para serotonina, insulina e polipeptídeo pancreático foram negativas. $\mathrm{O}$ diagnóstico foi de tumor de ilhotas, compatível com vipoma. A paciente teve alta sem intercorrências e continua assintomática nos três anos e meio após a cirurgia.

\section{Caso 4}

Homem, 38 anos, pardo, com história de úlceras pépticas recidivantes, com evolução de sete anos. Submeteu-se a três cirurgias para tratar a doença, sendo a última uma gastrectomia subtotal a BII, realizada um ano antes da internação. Apesar do tratamento clínico adequado, o paciente continuava com fortes dores epigástricas, anorexia e vômitos. Uma endoscopia digestiva alta revelou úlcera anastomótica de cinco centímetros de diâmetro. Havia suspeita de gastrinoma e a TC revelou massa sólida em cauda de pâncreas, de seis centímetros de diâmetro, com componente cístico-necrótico e calcificação de permeio. A gastrinemia era de $375 \mathrm{pg} / \mathrm{ml}$ (VR=90). Foi realizada a pancreatectomia distal, com esplenectomia. O exame histopatológico revelou tumor neuroendócrino multifocal. Estudos de imuno-histoquímica demonstraram positividade para cromogranina, somatostatina, sinaptofisina, polipeptídeo intestinal vasoativo e gastrina. A imunocoloração para insulina, polipeptídeo pancreático, serotonina e queratina foi negativa. O diagnóstico foi de tumor de ilhota pancreática. O paciente está assintomático por quatro anos e meio após a cirurgia.

\section{Caso 5}

Mulher, 17 anos, branca, teve um episódio de dor epigástrica de forte intensidade, persistindo por dois dias, sem história de úlcera, hipoglicemia ou diarréia. Uma TC revelou tumor de corpo de pâncreas, de 3,5x4,5 centímetros. Foi realizada a pancreatectomia de corpo e cauda, com esplenectomia. O resultado histológico foi "carcinóide/tumor de ilhota". A imunocoloração foi positiva para cromatogranina, somatostatina e peptídeo intestinal vasoativo. O diagnóstico final foi tumor de células da ilhota. A paciente teve bom resultado imediato e não tem queixas três anos após a operação.

\section{Caso 6}

Mulher, 31 anos, branca, referia dores epigástricas de pequena intensidade há cerca de três anos. Nos últimos dois meses as dores se tornaram mais intensas e acompanhadas de anorexia, náuseas e vômitos. A TC e a colangiopancreatografia endoscópica retrógrada revelaram tumor de cauda de pâncreas. À operação encontrouse tumoração na cauda do pâncreas, um linfonodo, próximo à borda superior da víscera, e quatro lesões esbranquiçadas, de um centímetro, sendo uma no lobo esquerdo do fígado e três no lobo direito, à direita do ligamento falciforme. $\mathrm{O}$ exame revelou adenocarcinoma. Foi realizada pancreatectomia de corpo e cauda, com esplenectomia, mas as lesões hepáticas foram consideradas irressecáveis. A paciente apresentou evolução favorável e, três anos após, suspeitou-se de um possível engano quanto ao diagnóstico. Um exame imuno-histoquímico foi positivo para cromogranina, enolase e sinaptofisina. A conclusão foi que os aspectos histoquímicos eram compatíveis com tumor neuroendócrino do pâncreas e a paciente tem apresentado evolução favorável nos três anos de pós-operatório.

\section{Caso 7}

Homem, 15 anos, branco, com queixas de dor epigástrica em queimação e vômitos em borra de café. Não referia diarréia em nenhuma fase da doença. Havia sido operado quatro anos antes, por úlceras pépticas de repetição e foi ressecado um tumor de cinco centímetros de diâmetro na face anterior do pâncreas, cujo resultado histopatológico foi gastrinoma. Uma endoscopia digestiva alta revelou bulbo duodenal deformado, com estenose e úlcera profunda no ápice, com sinais de sangramento recente. A ultra-sonografia revelou nódulo de lobo direito do fígado e a gastrinemia foi de $787 \mathrm{pg} / \mathrm{mL}(\mathrm{VR}=90)$. Submetido à gastrectomia subtotal, enucleação do tumor hepático e colecistectomia por motivos técnicos. Cinco anos após a primeira operação, o paciente não tem queixas, mas uma TC de controle demonstrou dois nódulos no lobo direito do fígado. 


\section{DISCUSSÃO}

A abordagem clínica e cirúrgica dos tumores neuroendócrinos constitui grande desafio para o médico, porque são raros e de características muito díspares e porque a tecnologia para o diagnóstico nem sempre é disponível, o que prejudica o planejamento cirúrgico e o prognóstico. Ainda assim, a evolução dos casos nos indica que as medidas tomadas foram adequadas e proporcionaram boa qualidade de vida e sobrevida aos pacientes.

Os gastrinomas esporádicos $(80 \%)$ foram descritos inicialmente em 1955 por Zollinger e Ellison, sendo a síndrome, caracterizada pela presença de ulceras de jejuno, hipersecreção gástrica e tumores de ilhota pancreáti$\mathrm{ca}^{12}$. Ao contrário das úlceras típicas, nesta síndrome as úlceras eram progressivas, persistentes e com freqüência causavam a morte do paciente. Posteriormente, a hipersecreção de gastrina foi associada com a etiopatogenia da doença e utilizada para o diagnóstico.

Gastrinomas são geralmente encontrados em pacientes entre 20 e 50 anos, são bem diferenciados, apresentam poucas mitoses e se assemelham a outros tumores pancreáticos. As células tumorais geralmente apresentam grânulos de secreção contendo outros peptídeos neuroendócrinos como o peptídeo intestinal vasoativo, insulina ou glucagon. Os sintomas mais freqüentemente associados às úlceras são a diarréia e a esofagite de refluxo ${ }^{13,14,15}$.

Valores de gastrina sérica em jejum superiores a $1.000 \mathrm{pg} / \mathrm{mL}(475 \mathrm{pmol} / \mathrm{L})$ são considerados diagnóstico para a síndrome de Zollinger-Ellison, contudo a maioria dos pacientes apresenta concentrações séricas entre 150 e $1.000 \mathrm{pg} / \mathrm{mL}$, dificultando assim o diagnóstico. Nestes casos, o único teste capaz de estabelecer o diagnóstico é o teste de estimulação com secretina. A secretina, em indivíduos normais, inibe a secreção de gastrina pelas células $\mathrm{G}$, mas em pacientes com SZE o resultado é oposto e o estímulo com secretina provoca um aumento drástico na gastrinemia $^{16,17}$.

É importante notar que um tumor neuroendócrino pode ocorrer como caso esporádico ou como componente integrante da síndrome de predisposição hereditária a neoplasias do sistema endócrino - NEM1 (neoplasia endócrina múltipla, tipo I). A NEM1 é uma doença autossômica dominante, caracterizada pela predisposição a tumores de paratireóides (penetrância de $90 \%$ até os 50 anos de idade), hipófise anterior e ilhotas pancreáticas ${ }^{14,15,18,19}$. Nestes pacientes, o duodeno é o sítio mais freqüente de gastrinomas, e nota-se também uma freqüência aumentada de tumores de tireóide, adenomas de supra-renais e lipomas. A maioria destes tumores são benignos, com exceção de alguns tumores de ilhotas pancreáticas e do trato gastrintestinal, que se tornam, assim, a principal causa de morte nos pacientes com NEM1 ${ }^{18,19}$.

A análise clínica e laboratorial do paciente nos permite inferir sobre a etiologia esporádica ou sindrômica da patologia, e o paciente deve ser tratado e acompanhado de acordo com as recomendações para a categoria na qual se enquadra. Tendo em vista, por exemplo, que na NEM1 a causa mais comum de sintomas clínicos está associada à síndrome de Zollinger-Ellison (SZE), que ocorre em aproximadamente $60 \%$ dos pacientes, e que freqüentes também são os insulinomas sintomáticos, devemos atentar para a sintomatologia correspondente nos pacientes com esta síndrome. De modo inverso, pouco comuns são os tumores produtores de peptídeo intestinal vasoativo (vipomas), do peptídeo pancreático (ppomas) e glucagonomas. No que diz respeito ao cirurgião, nos pacientes com NEM1 a ressecção cirúrgica nem sempre é eficiente em vista da natureza multifocal dos gastrinomas e da presença de pequenos gastrinomas duodenais de difícil detecção. Desta forma, o tratamento mais adequado para os gastrinomas associados com a NEM1 é a administração de inibidores da bomba de próton, que permitem o alívio dos sintomas associados à hiperacidez gástrica sem apresentar toxicidade importante.

Em uma análise individualizada de cada caso, podese notar que no Caso 1, apesar da aparente agressividade da lesão no momento do diagnóstico, o paciente sobreviveu sete anos, com boa qualidade de vida. Embora o estudo histoquímico não tenha sido possível neste caso, a apresentação clínica não sugere a produção de gastrina. A fístula digestiva apresentada se enquadra entre as complicações pós-operatórias mais comuns neste tipo de cirurgia ${ }^{20}$.

O Caso 2 exemplifica a variabilidade clínica e prognóstica dos tumores neuroendócrinos, as dificuldades diagnósticas e o risco inerente de qualquer procedimento cirúrgico de grande porte. Sem um quadro clínico característico, a paciente portava um tumor produtor de peptídeo intestinal vasoativo e somatostatina. $\mathrm{O}$ vipoma, tumor pouco frequiente, produz a síndrome de Verner e Morrison (diarréia aquosa abundante, hipocalemia e acloridria), mas poderia apresentar somente um sintoma. $\mathrm{O}$ somatostatinoma também causa diabetes tipo II, colelitíase e esteatorréia. A ausência de clínica que justificasse qualquer um destes tumores sugere que as substâncias detectadas pela imuno-histoquímica não eram secretadas para o meio extracelular, ou eram secretadas em quantidades insuficientes para causar manifestações clínicas.

Também no Caso 3, sem clínica característica de vipoma, o tumor não deveria ser secretante, o que poderia ser avaliado através de dosagens séricas. A colelitíase encontrada representa apenas uma das manifestações do somatostatinoma, sugerindo que os níveis séricos de somatostatina não deveriam ser elevados. Contudo, as síndromes causadas por estes peptídeos não apresentam necessariamente um quadro clínico completo, podendo se resumir a uma única manifestação. De maneira curiosa esta paciente apresentava um tumor misto de pâncreas, com um componente de células acinares descrito na literatura como caso raro entre os tumores neuroendócrinos (Tabela 1). Estes tumores podem ser classificados pelo critério TNM $^{5,6}$. Possivelmente a maioria dos sintomas descritos pela paciente (cólicas, vômitos e emagrecimento) foi causada pela litíase biliar e o tumor pancreático, ainda silencioso, foi detectado e ressecado em fase inicial, melhorando o prognóstico da paciente. 
No Caso 4, o caráter multifocal do tumor sugere a possibilidade de neoplasia endócrina múltipla, porém a investigação de hiperparatireoidismo e de tumores hipofisários resultou negativa. $\mathrm{O}$ exame imuno-histoquímico revelou a produção de gastrina, entre outros peptídeos, confirmando o diagnóstico de SZE. Não havia sintomatologia associada aos outros hormônios produzidos, ou possivelmente a intensidade das manifestações do gastrinoma mascarava os demais sintomas. Apesar da ausência de metástases e da sobrevida de quatro anos deste paciente, a possível associação com a síndrome NEM1 requer cuidados especiais no seu acompanhamento, devido a grande incidência de tumores do sistema endócrino, principalmente de paratireóide, hipófise anterior, pâncreas e tireóide.

No Caso 5, não há repercussão clínica associada aos hormônios identificados na imuno-histoquímica, sugerindo um tumor não secretante, ou níveis séricos pouco elevados. A raridade de tumores esporádicos nesta faixa etária orienta para a investigação de neoplasia endócrina múltipla.

No Caso 6, o estudo imuno-histoquímico excluiu adenocarcinoma de células ductais do pâncreas e revelou tumor produtor de cromogranina, enolase e sinaptofisina, confirmando um tumor neuroendócrino e justificando a sobrevida prolongada.

A manifestação da doença em idade precoce, como no Caso 7, também sugere um componente hereditário. $\mathrm{O}$ paciente foi operado várias vezes, como pode acontecer nos casos de SZE. Neste caso a investigação de hiperparatireoidismo também está indicada e a ressecabilidade das metástases hepáticas está sendo avaliada para garantir uma melhor sobrevida para o paciente.

Verifica-se, assim, que nestes pacientes, as síndromes não se manifestaram claramente, ainda que tenham tido o diagnóstico de gastrinomas, vipomas e carcinóide. Os exames por imuno-histoquímica demonstraram a presença de múltiplos hormônios, mas por falta de sintomas a correlação ficou prejudicada.

Os achados clínicos de prognóstico e sobrevida estão de acordo com aqueles relatados na literatura, contudo nota-se que a classificação dos tumores pelo tipo de hormônio produzido, identificado pela imuno-histoquímica, só se correlacionou com as manifestações endócrinas em um paciente com gastrinoma.

\begin{abstract}
Background: The purpose of the present study is to analyze the difficulties concerning diagnostic, prognostic and clinical conduct of seven patients with pancreatic neuroendocrine tumors (APUDomas), evaluated over the past decade. Methods: Patients varied in age from 15 to 66 years old, with a mean age of 38.4 years. All patients underwent some type of pancreatic resection as treatment of the neuroendocrine tumor. The histological sections were submitted to traditional and imunohistochemical examination. Results: Three patients were diagnosed with unspecific neuroendocrine tumor, two with VIPoma and two with Gastrinoma. Syndromes were not clearly manifested, although every case had a differential diagnosis. Imunohistochemistry showed the presence of multiple hormones, but due to the lack of clinical symptoms, correlation was harmed in most cases, however one Gastrinoma showed typical clinical symptoms. One patient died in the post-operative period, one survived for 7 years and five are still alive, with a life expectancy varying from 3 to 5 years. Conclusions: We observed a lack of typical clinical syndromes for most cases, but life expectancy was compatible with the one described in the literature.
\end{abstract}

Key Words: Apudomas; Neuroendocrine tumors; Carcinoids; Gastrinomas; Vipomas; Islet cell tumors.

\title{
REFERÊNCIAS
}

1. Kim JH, Ho SB, Montgomery CK et al. Cell lineage markers in human pancreatic cancer. Cancer,1990, 66: 2134-2143.

2. Stabile BE, Passaro E, Jr. Benign and malignant gastrinoma. Am J Surg,1985, 149: 144-150.

3. Trowers EA, Lazcano O, Swenson RE et al. Apudoma of the pancreas: benign or malignant? J Natl Med Assoc, 1989, 81: 601-603.

4. Capella C, La Rosa S, Uccella S et al. Mixed endocrineexocrine tumors of the gastrointestinal tract. Semin Diagn Pathol, 2000, 17: 91-103.

5. Fleming ID, Cooper JS, Henson DE et al. Manual for Staging of Cancer. Lippincott Raven, 5th edition. 1997.
6. Sobin LH, Fleming ID. TNM Classification of Malignant Tumors, fifth edition (1997). Union Internationale Contre le Cancer and the American Joint Committee on Cancer. Cancer,1997, 80: 1803-1804.

7. Larsson LI. Endocrine pancreatic tumors. Hum Pathol,1978, 9: 401-416.

8. Berney C, Kurt AM, Kapanci Y. Endocrine tumors of the pancreas: immunohistochemical and clinical correlation. Schweiz Med Wochenschr, 1994, 124: 179-185.

9. Dial PF, Braasch JW, Rossi RL et al. Management of nonfunctioning islet cell tumors of the pancreas. Surg Clin North Am, 1985, 65: 291-299.

10. Kent RB, III, van Heerden JA, Weiland LH. Nonfunctioning islet cell tumors. Ann Surg,1981, 193: 185-190. 
11. Madura JA, Cummings OW, Wiebke EA et al. Nonfunctioning islet cell tumors of the pancreas: a difficult diagnosis but one worth the effort. Am Surg, 1997, 63: 573-577.

12. Zollinger RM, Ellison EH. Primary peptic ulcerations of the jejunum associated with islet cell tumors of the pancreas. CA Cancer J Clin, 1989, 39:231-247.

13. Buetow PC, Miller DL, Parrino TV et al. Islet cell tumors of the pancreas: clinical, radiologic, and pathologic correlation in diagnosis and localization. Radiographics, 1997, 17: 453-472.

14. Marx S, Spiegel AM, Skarulis MC et al. Multiple endocrine neoplasia type 1: clinical and genetic topics. Ann Intern Med, 1998, 129: 484-494.

15. Marx SJ, Agarwal SK, Kester MB et al. Multiple endocrine neoplasia type 1: clinical and genetic features of the hereditary endocrine neoplasias. Recent Prog Horm Res, 1999, 54: 397-438.

16. Glaser B, Shapiro B, Glowniak J et al. Effects of secretin on the normal and pathological beta-cell. J Clin Endocrinol Metab, 1988, 66: 1138-1143.

17. Modlin IM, Jaffe BM, Sank A et al. The early diagnosis of gastrinoma. Ann Surg,1982, 196: 512-517.

18. Bartsch DK, Langer P, Wild A et al. Pancreaticoduodenal endocrine tumors in multiple endocrine neoplasia type 1: Surgery or surveillance?. Surgery, 2000, 128: 958965.
19. Thompson NW. The surgical management of hyperparathyroidism and endocrine disease of the pancreas in the multiple endocrine neoplasia type 1 patient. $\mathbf{J}$ Intern Med,1995, 238: 269-280.

20. Phan GQ, Yeo CJ, Hruban RH et al. Surgical experience with pancreatic and peripancreatic neuroendocrine tumors: review of 125 patients. J Gastrointest,1998, Surg 2: 472-482.

Endereço para correspondência

Olívio Louro Costa-TCBC

Rua Horácio Andrade de Carvalho 210 - Ilha do Boi 29052-620 - Vitória-ES

E-mail: olivio@terra.com.br 